\title{
A Case Report on a Rare Inherited Bone Marrow Failure Syndrome: Dyskeratosis Congenita.
}

\author{
MD. ANWARUL KARIM ${ }^{1}$, CHOWDHURY YAKUB JAMAL ${ }^{1}$, MD. IMRUL KAES ${ }^{2}$, KHONDAKER \\ MOBASHER AHMED ${ }^{3}$
}

\begin{abstract}
Dyskeratosis congenita is a rare type of inherited bone marrow failure syndromes (IBMFs) characterized by ectodermal dysplasia, bone marrow failure and cancer predisposition. Accelerated telomere shortening is supposed to be the causal mechanism of this disease. Features of ectodermal dysplasia appears early and may give clues of suspicion of forthcoming bone marrow disease. It has variable presentation and severe form of disease presents earlier. This a case report on a 2 year 2-month old boy who presented with features of bone marrow failure and had abnormality of skin, nail and oral mucosa.
\end{abstract}

Key word: Dyskeratosis congenita (DC)

\section{Introduction}

Dyskeratosis congenita (DC) is a rare inherited bone marrow failure syndrome. Dyskeratosis (Latin) means the irreversible degeneration of skin tissue, and congenita means inborn. First described in the medical literature in $1906 .{ }^{1}$ At that time DC was thought to be a disease of skin, nails and the mouth. Then in the later sixties, it was understood that patients with these ectodermal changes frequently progress to boneaplasia. Worth mention they also have cancer predisposition like other bone marrow failure syndromes. ${ }^{1}$

The prevalence of classic DC is approximately $1 /$ $1,000,000$ individuals in some part of the world, with 200 cases reported in the literature. ${ }^{2}$ In classical DC, ectodermal changes- triad of abnormal skin, dysplastic nails and oral leukoplakia appear first, often in the first decade of life and marrow aplasia develops later but in $>80 \%$ of cases are present by the $3 \mathrm{rd}$ decade. $^{3}$ Bone marrow failure is the main cause $(80 \%)$ of death which develops in around $85 \%$ of all cases. $^{4}$

1. Professor, Department of Paediatric Haematology \& Oncology, BSMMU.

2. Ex resident, Department of Paediatric Haematology \& Oncology, BSMMU.

3. Resident, Department of Paediatric Gastroenterology \& Nutrition, BSMMU.

Correspondence: Prof. Md. Anwarul Karim, Professor, Department of Paediatric Haematology \& Oncology, BSMMU. Dhaka. Cell no-01711269052, email no-

Received:

Accepted:
Severe variant of DC like Hoyeraal-Hreidarsson syndrome (HHS) has an early presentation characterized by early onset multisystem involvement, IUGR, microcephaly, developmental delay, bone marrow insufficiency, immunodeficiency, hypoplasia of brain, sometimes enteropathy and early mortality. ${ }^{5}$

Dyskeratosis is a genetically diverse disorder, showing autosomal recessive, autosomal dominant, and X-linked inheritance. There is also chance of sporadic case of DC. Though X linked form is higher in record. ${ }^{2}$

DC autosomal dominant (DKCA) forms DKCA2, DKCA3, DKCA4, DACA5 and DKCA6 are caused by mutation in the telomerase reverse transcriptase (TERT) gene (5p15); TINF2 (14q12); RTEL1 (20q13), TINF2 (14q12) and ACD (16q22) subsequently. Whereas autosomal recessive forms include $D K C B$, DKCB2, DKCB3, DKCB4, DKCB5, DKCB6 and DKCB7. In X-linked recessive DKCX (DC X-linked) is caused by mutation in the dyskerin gene on Xq28. Hoyeraal-Hreidarsson syndrome can be caused by mutation in several different DKC-associated genes, e.g., DKC1 TINF2, TERT and RTEL. ${ }^{2}$

Quicker telomere shortening is assumed to be the causal mechanism of this disease and in the severe forms of DC-HHS and the Revez syndrome the telomeres become critically short in early. ${ }^{6}$ The genes mutated in DC all are important for the telomerase 
enzyme function. Mutations of these genes jeopardize the action of the enzyme at the telomeres end. Subsequently the telomeres become so short that the cell halts growing or dies. This happens in all tissues, but fast dividing tissues such as the bone marrow, skin, and gut cells are affected the most as evidenced by decreased number of CD34+ cells and markedly reduced telomere lengths in these cells compared to controls..$^{7-9}$

This is a case report on an infant with DC.

\section{Case Report}

A 2 years 2 month old boy, $2^{\text {nd }}$ issue of nonconsanguineous parents was admitted with the complaints of recurrent fever and progressive pallor for 9 months, bleeding manifestations in the form of multiple blackish spots over skin for 3 months and recurrent oral ulceration along with whitish patch over tongue not responding to medication for several months. From $2^{\text {nd }}$ year of life, he developed difficulty in swallowing solid foods then he was on milk and rice powder preparation. He received packed blood cell transfusion prior to admission. On examination, the boy was playful, active, afebrile, moderately pale with stable vital signs like pulse, blood pressure and respiratory rate. He had whitish patch over tongue resembling leukoplakia along with ulceration in oral mucosa (Figure-1) and brittle fingers and toes nails (Figure-2).

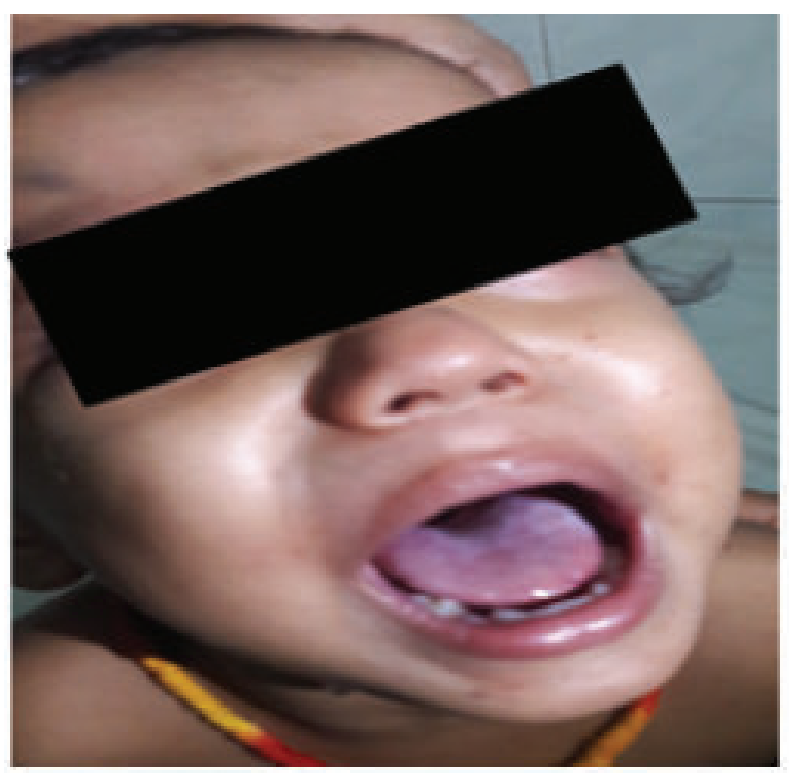

Fig.-1: Oral leukoplakia

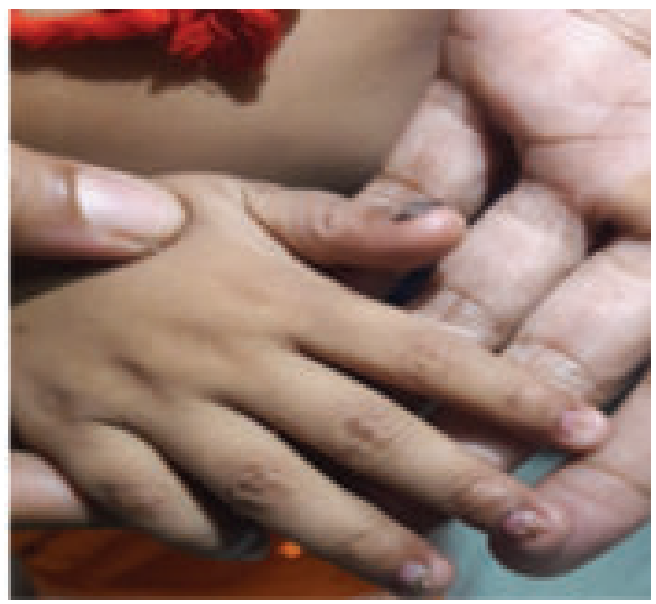

Fig.-2: Dystrophic nails

Anthropometrically he was severely underweight 8.3kg(WAZ:-3.75), severely stunted $87 \mathrm{~cm}$ (HAZ:3.1), severely wasted (WHZ:-3.3) with microcephaly $43 \mathrm{~cm}(z:-4.2)$. He had nonparalytic squint with leukocoria (white eye reflex) of right eye. Examination of hemopoietic system revealed that the boy was moderately pale and he had purpura and ecchymosis at different parts of the body more over lower limbs and trunk. Bony tenderness was absent and there was no lymphadenopathy, or organomegaly.

Table-I

Hisbloodexamination revealed

\begin{tabular}{lll}
\hline Investigation & Result & Normal reference Range \\
\hline $\mathrm{Hb}$ & $8.5 \mathrm{gm} / \mathrm{dl}$ & $12-16 \mathrm{~g} / \mathrm{dl}$ \\
$\mathrm{MCV}$ & $102.6 \mathrm{fl}$ & $76-96 \mathrm{ft}$ \\
$\mathrm{WBC}$ & $5910 / \mathrm{cmm}$ & $4000-11000 / \mathrm{cmm}$ \\
$\mathrm{ANC}$ & $640 / \mathrm{cmm}$ & $1500-8000 / \mathrm{cmm}$ \\
Platelet & $10,000 / \mathrm{cmm}$ & $150000-400000 / \mathrm{cmm}$ \\
\hline
\end{tabular}

He had macrocytic anemia (MCV $102 \mathrm{ft}$ ) with normal folic acid, vitamin B12 level and raised fetal $\mathrm{Hb}$ (15.3\%), neutropenia though normal WBC count and thrombocytopenia: hence pancytopenia.His coagulation profile like PT and APTT was normal with normal renal and liver function. His bone marrow was hypoplastic.

MRI of brain was done to see any associated congenital anomaly and revealed Cerebello-cerebral atrophy (cerebellum>cerebrum) and vermian hypoplasia (figure-3). 

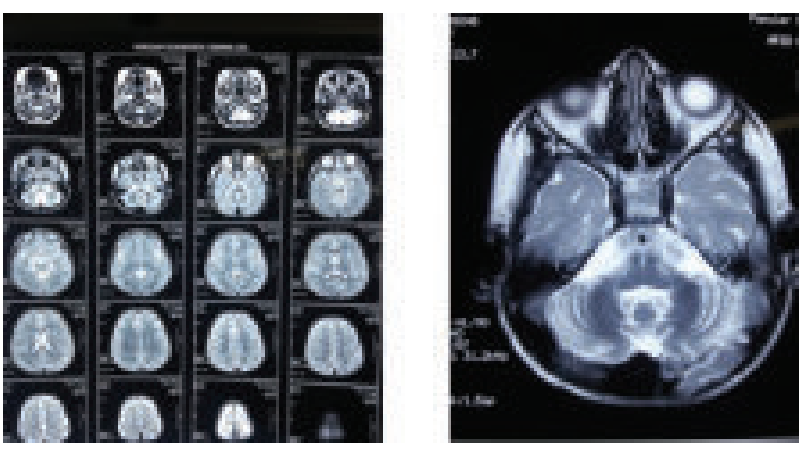

Fig.-3: MRI of brain Cerebello-cerebral atrophy (cerebellum>cerebrum) and vermian hypoplasia

Chromosomal study for telomere length and mutation analysis for confirmation of diagnosis was not possible due to financial constrain.

The child was treated with supportive care including transfusion with a plan to give androgen. Due to financial constrain patient party refused to continue treatment and went home and subsequently he died after 4 months of getting discharge from hospital due to bleeding.

\section{Discussion}

Dyskeratosis congenital(DC) also known as ZinsserEngman-Cole syndrome is a very infrequent inherited bone marrow failure syndrome with multi-system involvement. The classic clinical triad of abnormal skin pigmentation, leukoplakia, and nail dystrophy is not always observed. In its occult form the disease can present as aplastic anemia. ${ }^{3}$ This patient presented with features of pancytopenia as progressive pallor, recurrent infections, bleeding manifestations and he had all the three features of triad of ectodermal dysplasia - abnormal skin pigmentation, oral leukoplakia and brittle nails.

These ectodermal changes usually appear first, before the age of 10 years, and then bone marrow failure develops often before the age of 20 years. ${ }^{10}$ This specific case presented much early with feature of marrow failure, developmental delay, microcephaly and white eye reflex of eye. So, he was suspected as a case of Hoyeraal-Hreidarsson syndrome (HHS), which is a severe form of DC characterized by early onset multisystem involvement, IUGR, microcephaly, developmental delay, bone marrow insufficiency, immunodeficiency, hypoplasia of brain, sometimes enteropathy and early mortality. The boy had early presentation with these associated features. Abnormalities of the gut varying from malabsorption to severe inflammation with ulcers may be present, however this boy did not have any gastroenteral problem. Some cases of HHS associated with abnormalities of the eye like bilateral exudative retinopathy and Coats retinopathy; named as Revesz syndrome. ${ }^{11}$ The boy also had eye abnormality-white eye reflex of right eye,

Though genetic confirmation was not possible; classic clinical features of early onset of disease with ectodermal changes of nails, oral leukoplakia, marrow failure, microcephaly, brain abnormality, eye abnormality with negative TORCH matches with severe form of DC- HHS/Revesz syndrome.

There is no harmony about how to treat patients with DC. The treatment is focused on the specific symptoms of each individual. Supportive care such as infection control, judicial transfusion, oral care and use of moisturizing creams to avoid hurt to the skin.

Some specific treatment such as use of androgens; in about $69 \%$ cases can be expected to induce bone marrow function. ${ }^{12}$ Improvement of neutrophil count with use of GCSF or GMCSF was reported in few case reports. ${ }^{13}$ However; benefits of androgens and growth factors are brief. Allogenic hematopoietic stem cell transplantation is a potentially curative treatment of blood abnormalities associated with DC. ${ }^{14}$ Of 19 reported cases of DC patients who had HSCT from matched related donor, 11 survived more than 3 years of follow up. ${ }^{15}$

\section{Conclusion}

Reporting this case would add more information to the existing fund of knowledge of inherited bone marrow failure syndrome and will help clinicians to rapid recall of Dyskeratosis congenita (DC) as an important differential of skin, nail or mucosal changes with or without features of bone marrow failure.

\section{References}

1. Zinsser F. Atropha cutis reticularis pigmentation, dystrophiaungiumet leukoplakia oris. Ikonogr Dermatol. 1906; 5:219-23.

2. Dokal I. Dyskeratosis congenita in all its forms. British journal of haematology. 2000;110:768-79.

3. Savage SA, Alter BP. Dyskeratosis congenita. Hematol Oncol Clin North Am. 2009;23:215-31.

4. Kirwan M, Dokal I. Dyskeratosis congenita, stem cells and telomeres. Biochim Biophys Acta. 2009;1792:371-9.

5. Walne AJ, Vulliamy T, Kirwan M, Plagnol V, Dokal I. Constitutional mutations in RTEL1 cause severe dyskeratosis congenita. Am J Hum Genet. 2013;92:44853. 
6. Bessler M, Du HY, Gu B, Mason PJ. Dysfunctional telomeres and dyskeratosis congenita. Haematologica. 2007;92:1009-12.

7. Goldman FD, Aubert G, Klingelhutz AJ, Hills M, Cooper SR, Hamilton WS, et al. Characterization of primitive hematopoietic cells from patients with dyskeratosis congenita. Blood. 2008;111(9):4523-31.

8. Vulliamy T, Marrone A, Goldman F, Dearlove A, Bessler $\mathrm{M}$, Mason PJ, et al. The RNA component of telomerase is mutated in autosomal dominant dyskeratosis congenita. Nature. 2001;413 (6854): 432-5.

9. Alter BP, Gardner FH, Hall RE. Treatment of dyskeratosis congenita with granulocyte colony stimulating factor and erythropoietin. British journal of haematology. 1997;97: 309-11.

10. Walne AJ, Dokal I. Advances in the understanding of dyskeratosis congenita. British journal of haematology. 2009;145(2):164-72.

11. Revesz T, Fletcher S, Al-Gazali LI, DeBuse P. Bilateral retinopathy, aplastic anaemia, and central nervous system abnormalities: a new syndrome?. J Med Genet. 1992;29: 673-5.

12. Khincha PP, Wentzensen IM, Giri N, Alter BP, Savage SA. Response to androgen therapy in patients with dyskeratosis congenita. British journal of haematology. 2014;165:34957.

13. Erduran E, Hacisalihoglu S, Ozoran Y. Treatment of dyskeratosis congenita with granulocyte-macrophage colony-stimulating factor and erythropoietin. J Pediatr Hematol Oncol. 2003;25: 333-5.

14. Langston AA, Sanders JE, Deeg HJ, Crawford SW, Anasetti $\mathrm{C}$, et al. Allogeneic marrow transplantation for aplastic anaemia associated with dyskeratosis congenita. British journal of haematology. 1996; 92:758-65.

15. Dror $\mathrm{Y}$, Freedman MH, Leaker M, Verbeek J, Armstrong $C A$, et al. Low-intensity hematopoietic stem-cell transplantation across human leucocyte antigen barriers in dyskeratosis congenita. Bone marrow transplant. 2003;31:847-50. 